16 a 18 de outubro de 2019 - Campinas | Brasil

\title{
Metaheurística Evolutiva para o Problema de Rotação de Culturas
}

\author{
Rodrigo G. R. Mendonça*, Priscila B. Rampazzo.
}

\begin{abstract}
Resumo
O agronegócio é um setor importante no Brasil, sendo responsável por um em cada três empregos e 21,6\% do Produto Interno Bruto (PIB) em 2017 segundo o Ministério da Agricultura, Pecuária e Abastecimento. Para que esse setor continue contribuindo para a economia do país, é importante melhorar seus precessos, aumentando sua eficiência. Para isso, pode-se fazer uso dos métodos de otimização, que buscarão uma solução ótima, ou a mais próxima possível da ótima, que resolva o problema em questão. Esse trabalho se utiliza de um desses métodos, um Algoritmo Genético (GA), que pertence a classe das Metaheurísticas Evolutivas, para encontrar uma solução para o Problema de Rotação de Culturas (CRP), com o objetivo de aumentar a lucratividade do cultivo dos proprietários de terras do Brasil.
\end{abstract}

\section{Palavras-chave:}

Rotação de Culturas, Sequenciamento de Tarefas, Algoritmos Genéticos

\section{Introdução}

A fim de otimizar a utilização de recursos no agronegócio, a Pesquisa Operacional está sendo utilizada para encontrar soluções para os mais diversos problemas encontrados no setor, que variam desde o controle da frota de máquinas necessárias ao plantio e à colheita[2] até a escolha de quais espécies cultivar em determinado período[1]. Este trabalho tem como objetivo analisar este último caso, focando principalmente no Problema de Rotação de Culturas (Crop Rotation Problem, ou CRP).

O CRP consiste em determinar uma sequência de plantas que serão cultivadas em determinado espaço de tempo a fim de otimizar a rendimento obtido, considerando uma utilização a longo prazo[1]. É utilizado como parâmetros uma lista de espécies que se tem interesse em cultivar, uma lista dos terrenos que serão utilizados para o cultivo, juntamente com o tamanho de cada terreno, e outras restrições, que dependem da especificidade de cada caso; tais restrições podem ser de demanda, de qualidade de solo, necessidade de períodos de adubação verde ou de descanso do solo, entre outras.

O problema analisado nesse trabalho se utilizou das seguintes restrições: de demanda, a qual se não for atendida penaliza o rendimento obtido (que nesse caso é o lucro obtido pela sequência escolhida para o CRP); de sazonalidade, que indica em qual período do ano pode ocorrer o cultivo de cada planta; de sequência, que determina que duas plantas da mesma família não podem ser plantadas uma depois da outra no mesmo terreno; e de adjacência, que penaliza o rendimento caso plantas da mesma família sejam plantadas em terrenos adjacentes no mesmo período de tempo (simulando uma maior propensão à pragas devido ao cultivo simultâneo da mesma família de plantas).

Para encontrar uma solução para o problema proposto, utilizou-se de um Algoritmo Genético (Genetic Algorithm, ou GA) com otimização de um único objetivo (a lucratividade obtida pelo $\mathrm{CRP}$ ). O GA, pertencente à classe das Metaheurísticas Evolutivas, é um método de resolução baseado no conceito de seleção natural. 0 método consiste em modificar constantemente um conjunto inicial de soluções (população inicial) durante $\mathrm{N}$ ciclos (gerações); em cada ciclo, as soluções (indivíduos) passam por crossover, gerando novas soluções (filhos) que sofrem mutações e seguem para a próxima geração; após essa sucessão de gerações, a população inicialmente aleatória "evolui" durante o processo iterativo, tendendo à uma solução de qualidade para o problema inicial.

\section{Resultados e Discussão}

Com a programa desenvolvido se utilizando de um GA para encontrar soluções para o CRP apresentado inicialmente, foi possível observar o comportamento de uma população de 100 indivíduos inicialmente aleatórios com o passar de 100 gerações; tal comportamento está apresentado na Figura 1.

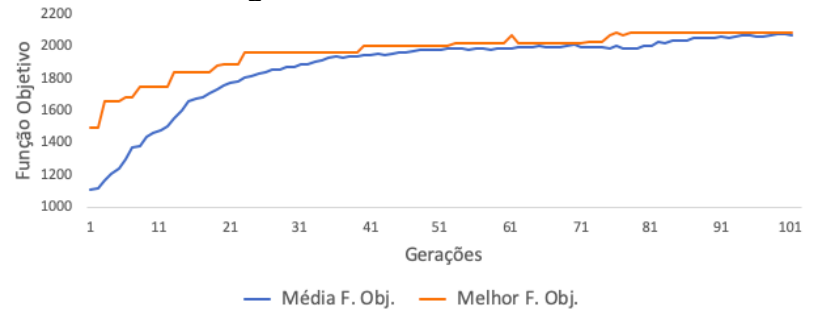

Figura 1: Comportamento da população do GA.

Com o método, foi possível partir de uma solução inicial com valor da função objetivo de 1492 e chegar em uma solução com função objetivo 2088. Esse resultado demonstra a efetividade do programa, pois ele conseguiu melhorar a solução inicial em quase $40 \%$.

\section{Conclusões}

Pode-se concluir que o programa desenvolvido é eficiente, visto o aumento obtido na solução após apenas 100 gerações.

A partir desse trabalho, tem-se em vista a possibilidade de aprimorá-lo, buscando mudar para análise multiobjetivo do CRP, visando assim refletir melhor os problemas reais encontrados no país.

\section{Agradecimentos}

Agradecimentos ao Conselho Nacional de Desenvolvimento Científico e Tecnológico (CNPq) e ao programa Institucional de Bolsas de Iniciação Científica (PIBIC-UNICAMP) pelo suporte financeiro.

\footnotetext{
[1] Detlefsen, N. Crop rotation modelling. In Proceedings of the EWDA-04 European workshop for decision problems in agriculture and natural resources. Silsoe Research Institute, England, 2004; pp 5-14

${ }^{[2]}$ Sørensen, C. G.; Bochtis, D. D. Conceptual model of fleet management in agriculture. Biosystems Engineering, 2010; Vol. 105; pp 41-50
} 